\title{
Comparative analysis of proteome maps of silkworm hemolymph during different developmental stages
}

\author{
Yong Hou, Yong Zou, Fei Wang, Jing Gong, Xiaowu Zhong, Qingyou Xia, Ping Zhao*
}

\begin{abstract}
Background: The silkworm Bombyx mori is a lepidopteran insect with four developmental stages: egg, larva (caterpillar), pupa, and adult. The hemolymph of the silkworm is in an open system that circulates among all organs, and functions in nutrient and hormone transport, injury, and immunity. To understand the intricate developmental mechanisms of metamorphosis, silkworm hemolymph from different developmental stages, including the $3^{\text {rd }}$ day of fifth instar, the $6^{\text {th }}$ day of fifth instar, the $3^{\text {rd }}$ day of pupation, the $8^{\text {th }}$ day of pupal stage and the first day of the moth stage, was investigated by two-dimensional electrophoresis and mass spectrometry.

Results: Two-dimensional polyacrylamide gel electrophoresis showed that from the larval to moth stages, silkworm hemolymph proteins changed markedly. Not only did major proteins such as SP1, SP2, and the $30 \mathrm{~K}$ lipoprotein change, but other proteins varied greatly at different stages. To understand the functions of these proteins in silkworm development, 56 spots were excised from gels for analysis by matrix-assisted laser desorption ionization time-of-flight mass spectrometry (MALDI-TOF MS). We identified 34 proteins involved in metamorphosis, programmed cell death, food digestion, metabolism, and nutrient storage and transport. Most proteins showed different expression at different stages, suggesting functions in development and metamorphosis. An abundance of proteins related to immunity were found, including hemolin, prophenoloxidase, serine proteinase-like protein, paralytic peptide-binding protein, and protease inhibitor.

Conclusions: Proteomics research not only provides the opportunity for direct investigation of protein expression patterns, but also identifies many attractive candidates for further study. Two-dimensional maps of hemolymph proteins expressed during the growth and metamorphosis of the silkworm offer important insights into hemolymph function and insect metamorphosis.
\end{abstract}

\section{Background}

The mulberry silkworm, Bombyx mori, has been raised for more than 5000 years in Asian countries, and is a major economic resource for many families. Currently, the silkworm is not only a domesticated insect used for silk production, but is also a model lepidopteran for pest control studies. The silkworm has an open circulatory system containing hemolymph, which surrounds the tissues of the silkworm with blood. Nutrients and oxygen are delivered to all parts of the silkworm body through the hemolymph, which is also an important depository for nutrition and energy. After eating, the

\footnotetext{
* Correspondence: zhaop@swu.edu.cn

College of Biotechnology, Institute of Sericulture and Systems Biology, Southwest University, Chongqing 400716, PR China
}

percentage of hemolymph in the silkworm increases as a proportion of body weight, while a silkworm that is starved or has just finished ecdysis has a reduced proportion of hemolymph. In addition, hemolymph has a key role in innate immunity response, that is triggered when bacteria or fungi enter the silkworm body [1].

Since the $1970 \mathrm{~s}$ and earlier, the proteins of silkworm hemolymph have been studied to elucidate their role in silkworm development. In 1953, Telfer identified vitellogenin, a female-specific protein in the hemolymph of Hyalophora cecropia, as the first vitellogenin found in insects [2]. In $1980 \mathrm{~s}$, two major proteins, SP1 (storage protein 1) and SP2 (storage protein 2), were discovered in silkworm larval hemolymph. These two proteins show clear variability and sex-differentiation during last 
instar stage development [3,4]. In 1981, a group of structurally related proteins called $30 \mathrm{~K}$ proteins because of their approximate molecular weights of 30,000 Da, were found to be stored in the larval hemolymph of silkworms in a stage-dependent fashion. The $30 \mathrm{~K}$ proteins are minimally detectable in the hemolymph before day 3 of the fifth larval instar, but become major hemolymph proteins in the early pupal stage because of progressive increase in expression after the $3^{\text {rd }}$ day of fifth instar larvae [5]. After genome maps of the silkworm were published in 2004 and 2008 [6,7], proteomic technology was applied to silkworm research. Proteomic tools, particularly two-dimensional (2D)-electrophoresis in conjunction with mass spectrometry have been used to analyze silkglands, fatbody, skeletal muscle, and hemolymph proteins [8-11]. In this work, hemolymph proteins from different developmental stages were investigated by 2Delectrophoresis and matrix-assisted laser desorption ionization time-of-flight mass spectrometry (MALDITOF MS), to construct a profile of silkworm hemolymph proteins from larva to moth, to aid in a comprehensive understanding of silkworm metamorphosis.

\section{Results}

SDS-PAGE of silkworm hemolymph protein from $1^{\text {st }}$ day of fifth instar to moth

Silkworm hemolymph from the $1^{\text {st }}$ day of fifth instar to eclosion was collected and analyzed by SDS-PAGE (Fig. 1). During this period, silkworms underwent two dramatic morphological transitions, pupation and

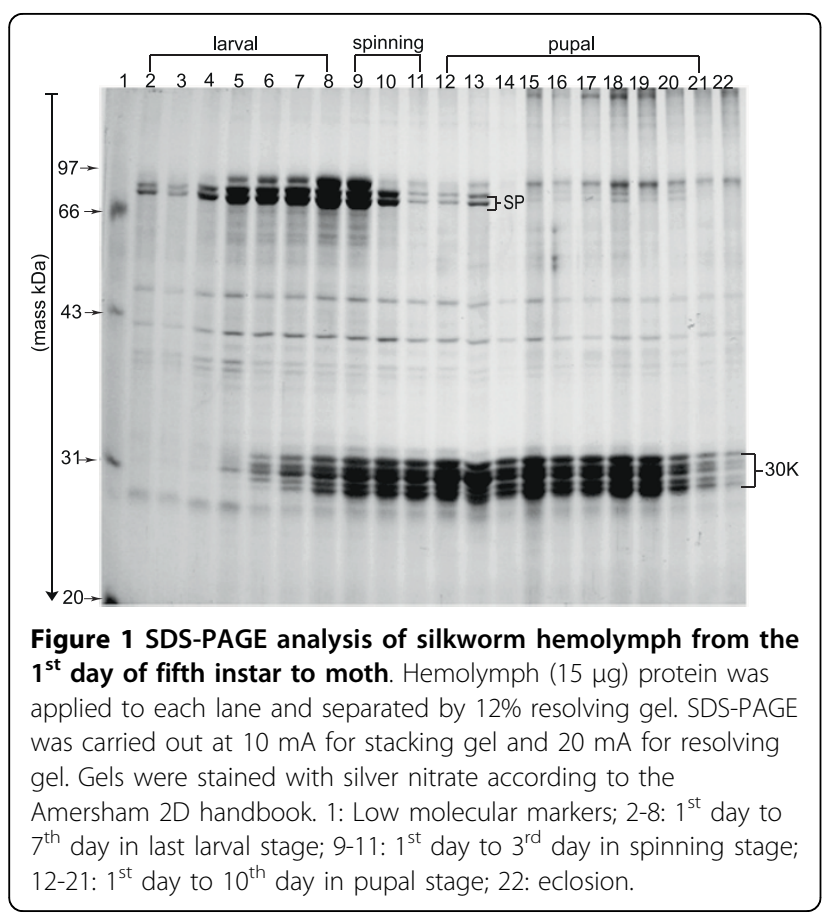

eclosion. The SDS-PAGE map showed that hemolymph proteins, particularly the proteins around $30 \mathrm{kDa}$ and 80 $\mathrm{kDa}$, underwent dramatic changes. Proteins around 80 $\mathrm{kDa}$ were detected at the $1^{\text {st }}$ day of fifth instar, and their expression level gradually increased from the $3^{\text {rd }}$ day of fifth instar, reaching a maximum at the wandering stage, then descending acutely, and almost disappearing during pupation. Proteins of approximately $30 \mathrm{kDa}$ appeared in the hemolymph at the $4^{\text {th }}$ day of fifth instar, increased gradually as the silkworm grew, and became a major component of hemolymph in pupation. At the late pupa stage, proteins around $30 \mathrm{kDa}$ began to decrease, almost disappearing during eclosion. By molecular weight and expression patterns, these proteins were predicted to be storage proteins and $30 \mathrm{~K}$ proteins of silkworm hemolymph [12]. They were expressed in the fatbody and secreted to the hemolymph, and constituted the major part of plasma proteins. Considering the limitation of SDS-PAGE resolution, a few samples were selected for further analysis by $2 \mathrm{D}$-electrophoresis.

\section{Two-dimensional electrophoresis of silkworm hemolymph at different stages}

Samples from the $3^{\text {rd }}$ day of fifth instar (L3), the $6^{\text {th }}$ day of fifth instar (L6), the $3^{\text {rd }}$ day of pupation, the $8^{\text {th }}$ day of pupa, and eclosion were selected for analysis by 2Delectrophoresis. Total proteins from each sample were separated by 2D-electrophoresis at $\mathrm{pH}$ 3-10 (Fig. 2). The results show that approximately 128 spots proteins were observed from the L3 map of the male silkworm. The proteins ranged from 20 to $97 \mathrm{kDa}$ in molecular mass, and from $\mathrm{pH} 4$ to 10 in pI. Similar patterns were displayed on three replicate gels, with an average matching rate of more than $96 \%$ between replicates. From L3, proteins in the range of $28-31 \mathrm{kDa}$ molecular mass were up-regulated sharply, so that separation at L6 and P3 was difficult to map. Vertical stripes appeared because of the large quantity of proteins in the $30 \mathrm{kDa}$ region. In the $2 \mathrm{D}$ hemolymph map from the $8^{\text {th }}$ day of pupation and in moths, these stripes were well separated because of decreased expression of the proteins around $30 \mathrm{kDa}$. Some sex-specific proteins were observed in female, but not male silkworm hemolymph, such as spot $\mathrm{H} 50$ at 42 $\mathrm{kDa}$. The change in proteins by 2D-PAGE was consistent with the SDS-PAGE analysis. The high resolution of 2D-electrophoresis made it possible to study gel-separated proteins by MALDI-TOF MS.

\section{Identification of excised spots from the hemolymph 2D map}

To understand the change in silkworm hemolymph proteins, 56 spots were excised for analysis by MALDI-TOF MS. The results identified by peptide mass fingerprinting are in Additional File 1. To clarify the change in 


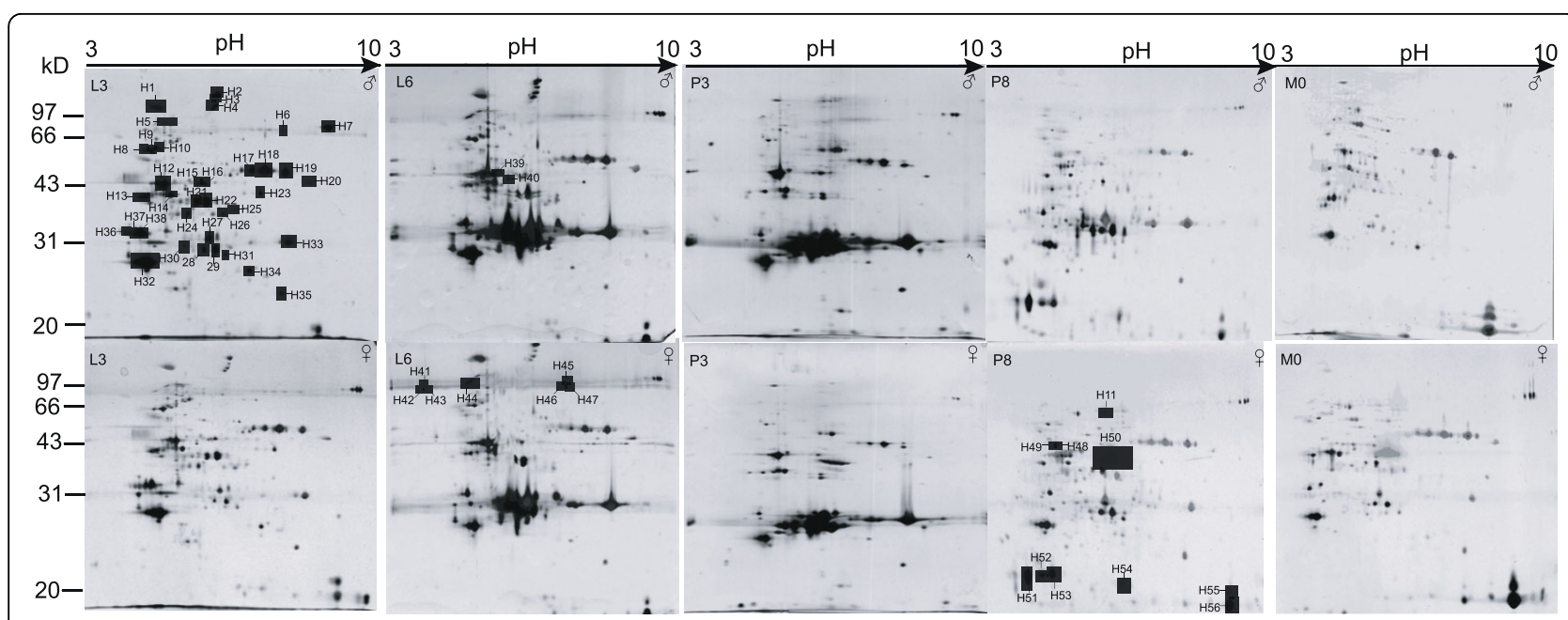

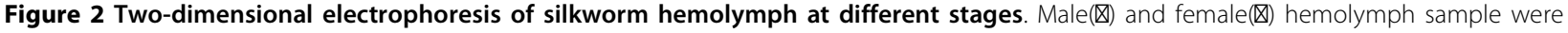
subjected to 2D-electrophoresis separately. Protein $(60 \mu \mathrm{g}$ ) was separated by IEF using $13 \mathrm{~cm}$ IPG strips (pH 3-10), followed by $12.5 \%$ SDS-PAGE and silver-staining. L3: $3^{\text {rd }}$ day fifth instar larva; L6: $6^{\text {th }}$ day fifth instar larval; P3: $3^{\text {rd }}$ day pupa; P8: $8^{\text {th }}$ day pupa; M0: eclosion. Circles indicate 56 spots excised for MALDI-TOF MS, most of which had different expression during development and metamorphosis.

hemolymph proteins during development and metamorphosis, the proteins were displayed by partial maps (Fig. 3 ). The results showed more than 20 spots expressed at their highest level during the larval stage, including $\mathrm{H} 1$, H2, H3, H4, H5, H6, H7, H8, H9, H10, H20, H21, H22, $\mathrm{H} 23, \mathrm{H} 24, \mathrm{H} 25, \mathrm{H} 26, \mathrm{H} 40$, and H41-47. Eleven spots had the highest level in pupa: H11, H27, H28, H29, $\mathrm{H} 33, \mathrm{H} 48, \mathrm{H} 49, \mathrm{H} 50, \mathrm{H} 51, \mathrm{H} 52$ and H53, and only few spots $(\mathrm{H} 55, \mathrm{H} 56)$ were seen in the moth stage. Some proteins displayed consistent expression from the $5^{\text {th }}$ instar larval stage to the moth stage, such as H17, H18, H19. Among these proteins, some have been reported previously, such as vitellogenin (H50), while others were first identified in this work, such as $\mathrm{H} 20, \mathrm{H} 23$, and $\mathrm{H} 25$. To make a profile of silkworm hemolymph $30 \mathrm{~K}$ proteins, 15 additional spots were cut from this area for MALDI-TOF MS (Fig. 4). Five $30 \mathrm{~K}$ proteins were obtained from the $3^{\text {rd }}$ day pupa hemolymph. Because of the abundance of $30 \mathrm{~K}$ proteins in hemolymph, a silverstained spot on a 2D-gel may contain several overlapping proteins. For example, both of Bmlp1 and Bmlp4 were present in spot 8 , and could be identified clearly by their specific peptide mass (Fig. 5). Some proteins, however, were constitutively detected in multiple spots. For example, Bmlp7 was identified from spots 13, 14 and 15; and Bmlp1 was identified in spots 6, 11 and 12 (Additional File 2). Isoforms of proteins with unique pI values might occur because of post-translation modifications, such as phosphorylation. To validate the identification from peptide mass fingerprint, some peptides were analyzed by MS/MS. Fragment ion segments from the precursor ions confirmed the results of peptide mass fingerprint (Fig. 5).

\section{Discussion}

In 2009, Kajiwara investigated the proteome of silkworm hemolymph by 2D-mapping and ion-trap mass spectrometry, and identified 67 proteins in a hemolymph map of the $3^{\text {rd }}$ day of fifth instar [13]. After comparing the 56 proteins identified in this work with those 67 proteins, we found only 5 that were identical, including juvenile hormonebinding proteins (spots H36-38); aldose reductase (spots H21, H22); low molecular-weight lipid proteins (spots $\mathrm{H} 27, \mathrm{H} 28$ and H29); and CI8 (spot H12). Other proteins identified by Kajiwara, such as RNA-binding proteins, carboxylesterases, zinc-finger proteins, and some hypothetical proteins, were not identified in this work. Comparing the hemolymph map of Kajiwara with the hemolymph map from this work, we found the $\mathrm{pH}$ range of the two maps was different. We used $\mathrm{pH}$ 3-10 strips to separate proteins, while Kajiwara used pH 4-7 strips. For this reason, some alkaline proteins in this work may not appear in the Kajiwara map, such as imaginal disk growth factor (spot H1719), gelsolin (spot H20), and glyoxylate reductase (spot H23). We also compared our 2D map with the 2D map of Manduca hemolymph reported by Furusawa in 2007 [14], and found 10 Manduca hemolymph proteins had similar expression patterns in silkworm hemolymph protein, including transferrin protein, serine proteinase-like protein, chymotrypsin inhibitor, hemolin and prophenoloxidase. Thus, our results contribute to the understanding of development and metamorphosis not only in the silkworm, but also in other lepidopteran pests.

\section{$30 \mathrm{~K}$ protein of silkworm hemolymph}

$30 \mathrm{~K}$ proteins, a group of lipoproteins with a molecular mass of approximately $30 \mathrm{kDa}$, accumulate in a 


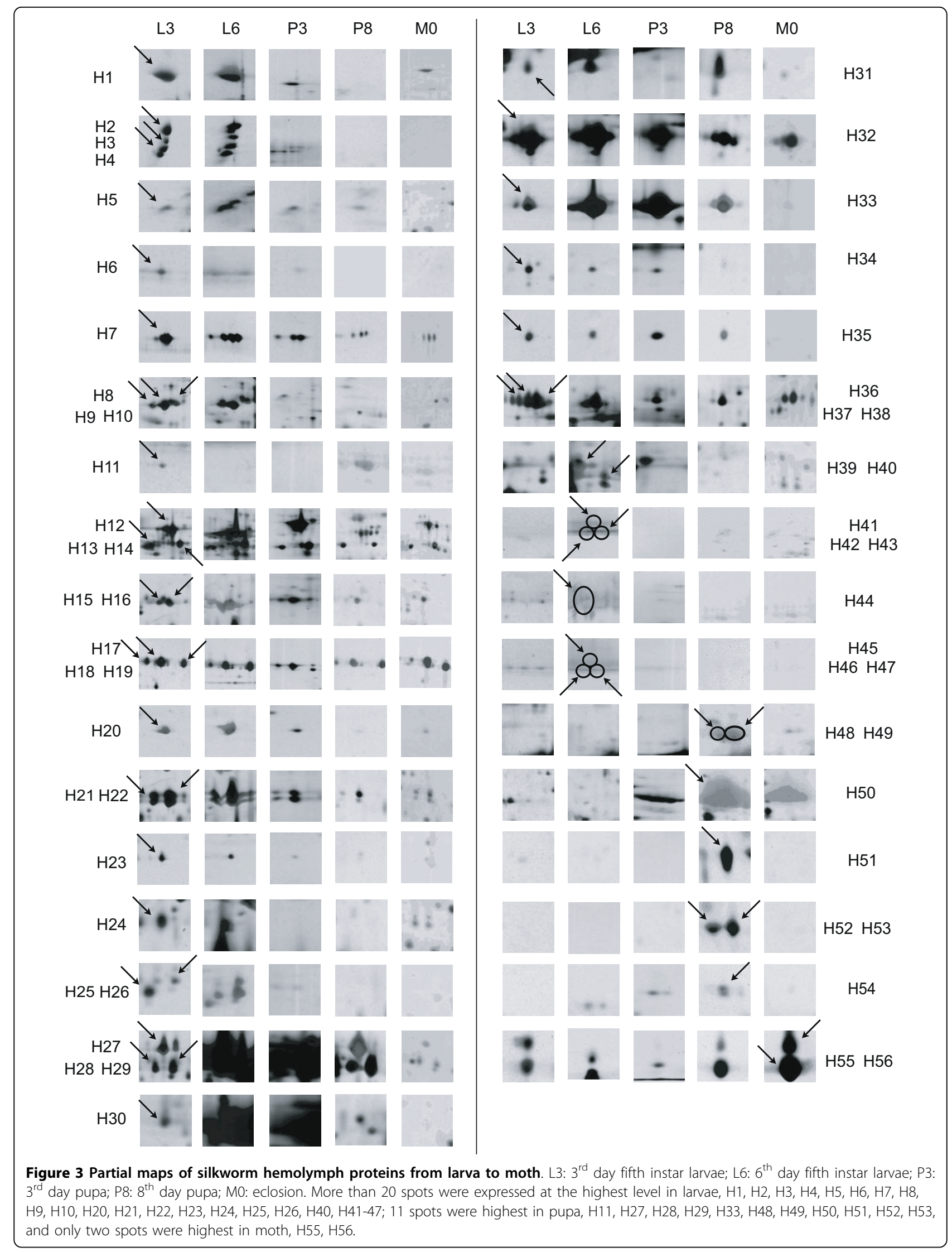




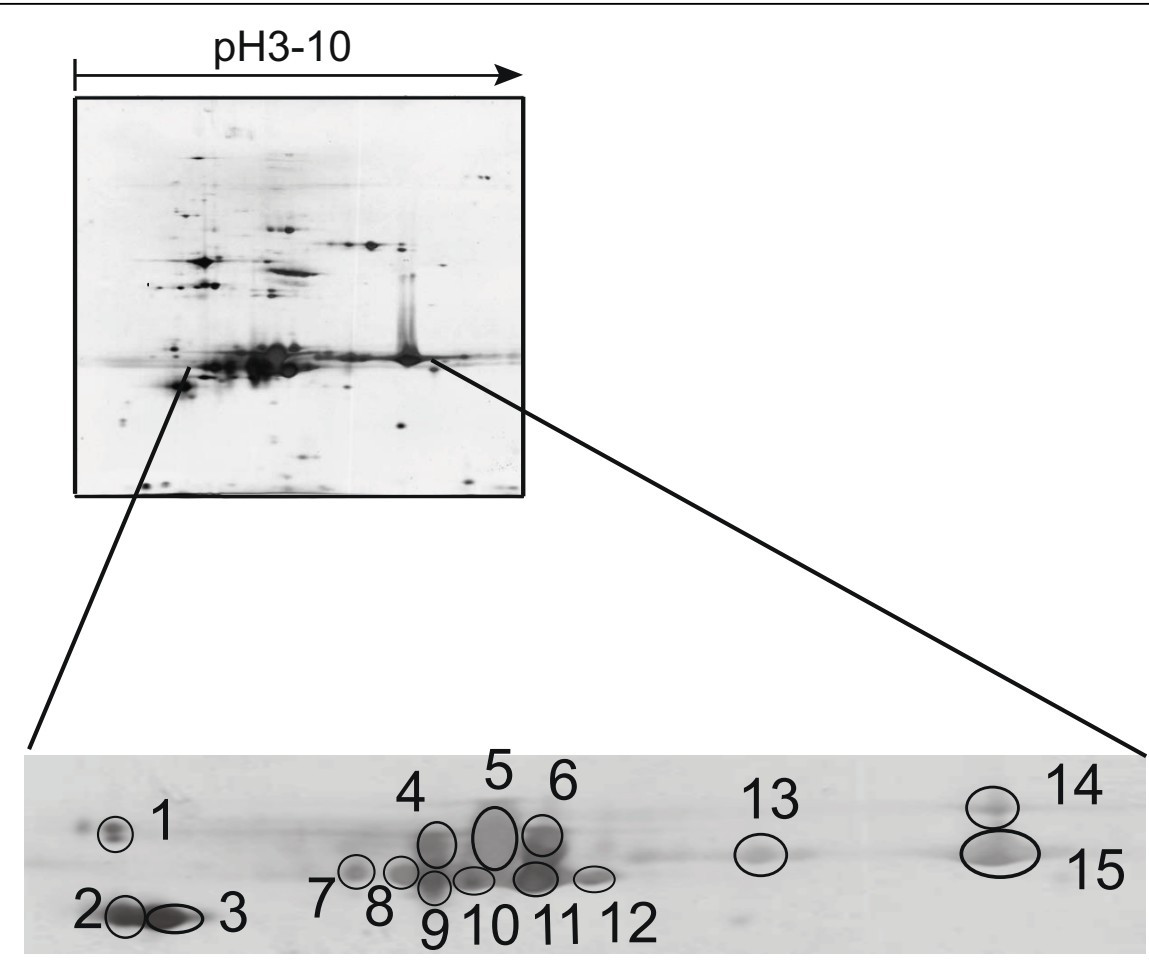

Figure 4 Identification of $\mathbf{3 0} \mathrm{K}$ proteins in silkworm hemolymph from $\mathbf{3}^{\text {rd }}$ day of pupation by MALDI-TOF MS. The enlarged part is the area from 27 kD-31 kD of 2D gel, where 15 spots indicated by circles were excised to be analyzed by MALDI-TOF MS spectrometry.

stage-dependent fashion in the larval hemolymph of the silkworm, Bombyx mori. In previous work, we analyzed the silkworm genome and expressed sequences, and found 10 genes encoding $30 \mathrm{~K}$ proteins. By semi-quantitative reverse-transcription polymerase chain reaction, eight members were found to be expressed in the fatbody [15]. In this work, we investigated the $30 \mathrm{~K}$ proteins of hemolymph at the protein level using 2D-PAGE and MALDITOF MS. Expression of hemolymph $30 \mathrm{~K}$ proteins demonstrated a dynamic change from the $1^{\text {st }}$ day of fifth instar larvae through eclosion, with maximum expression at the spinning stage, and almost disappearance by the $1^{\text {st }}$ day of moth stage. Five $30 \mathrm{~K}$ protein family members were identified from the 28-31 $\mathrm{kDa}$ area in the hemolymph of $3^{\text {rd }}$ day pupa (Additional File 2). The proteins sequences of Bmlp1, Bmlp2, Bmlp3 and Bmlp4 had more than 97\% similarity with PBMHP-6, PBMHP-12, PBMHPC-19 and PBMHPC-21, low molecular lipoprotein $30 \mathrm{~K}$ of silkworm which were reported previously by Sakai [16]. Because of the high similarity, these might be the same proteins in silkworm, which show some genetic variation in different varieties. Bmlp7 is a novel $30 \mathrm{~K}$ protein in hemolymph, and shared $93 \%$ protein sequence similarity with PBMHPC-19. Other members were not detected in hemolymph because of low expression, or expression during other stages.
In the hemolymph map of the $3^{\text {rd }}$ day of fifth instar, Bmlp1, Bmlp2, Bmlp3 and Bmlp7 were found by MS, but not Bmlp4. Bmlp4 increased sharply during development, and was detected in six spots (spot 1, 4, 7, 8, 9, $10)$ in the hemolymph map of the $3^{\text {rd }}$ day of pupation. After metamorphosis from silkworm to pupa, it decreased rapidly in the hemolymph, and was not detected in the hemolymph at the $8^{\text {th }}$ day of pupation. Compared to Bmlp1, Bmlp2, Bmlp3 and Bmlp7, Bmlp4 is a special $30 \mathrm{~K}$ protein that appears later in the fifth instar stage, is expressed strongly, and disappears rapidly. This is similar to the mRNA expression of Bmlp4 in fatbody that was reported by Sun in 2007 [15]. These results suggested that Bmlp4 may have a different function than other silkworm $30 \mathrm{~K}$ proteins.

During the later pupal stages, female silkworm proteins around $30 \mathrm{kD}$ were reduced compared to males. It has been reported that during this period, the $30 \mathrm{~K}$ proteins were transported into the embryo in female silkworms, and became important for embryonic development $[17,18]$, which would result in the reduction of $30 \mathrm{kD}$ in female hemolymph. While in male silkworms, the $30 \mathrm{~K}$ proteins accumulated in the hemolymph instead of being absorbed by the embryo. Interestingly, at the $8^{\text {th }}$ day of pupation, the amount of $30 \mathrm{~K}$ proteins decreased sharply, both in females and males. 

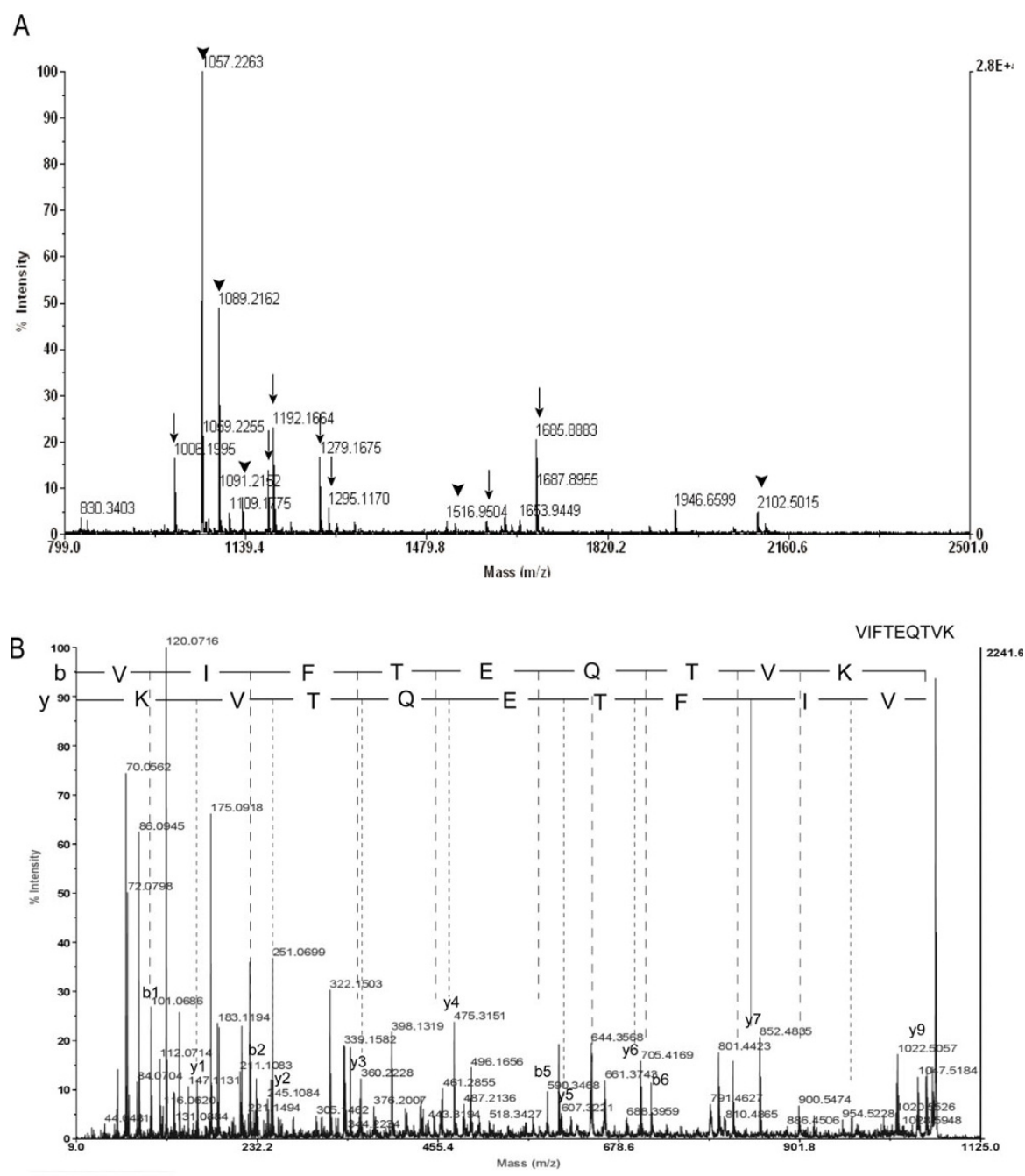

\section{C}

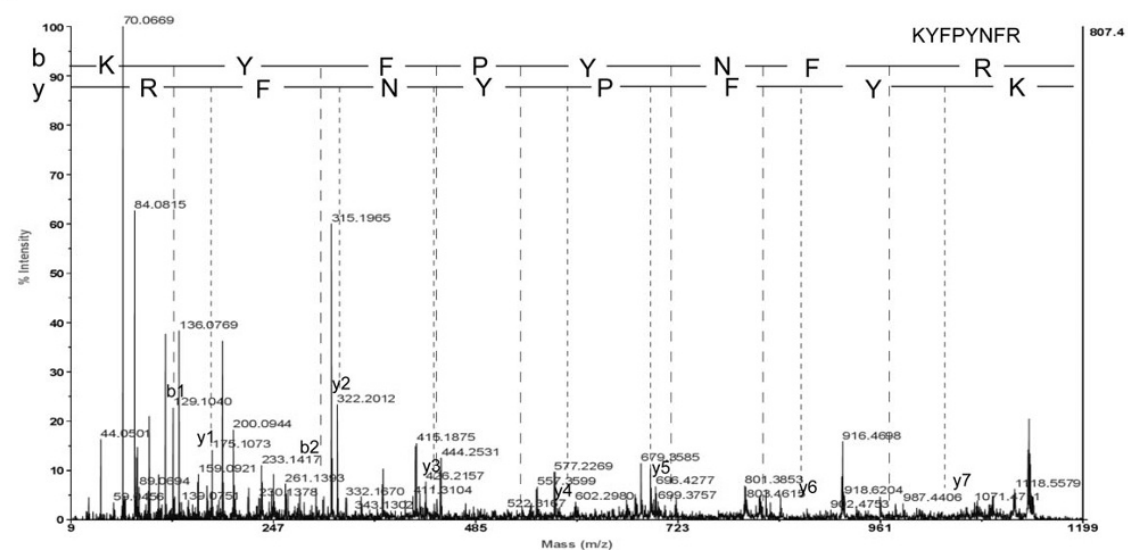

Figure 5 Identification of spot 8 from $3^{\text {rd }}$ day of pupation by peptide mass fingerprint and MS/MS. Spot 8 was excised from gels and digested with trypsin, and the resulting peptides were analyzed using MALDI-TOF mass spectrometry and TOF/TOF mass spectrometer. (A) MALDI-TOF MS on in-gel-digested peptides of spot 8 . A total of 22 deisotoped peptide masses were submitted to a database search, and 14 peptides matched two members of the $30 \mathrm{~K}$ protein family of silkworm. Arrows indicate peptides from Bmlp4. Arrowheads indicate peptides from Bmlp1. (B) MS/MS spectra of ion 1064.28 from Bmlp1. (C) MS/MS spectra of ion 1134.25 from Bmlp4. Fragment ion segments from the precursor ions confirmed the results of peptide mass fingerprint. The $y$ and $b$ ions and their corresponding peptide sequences are shown. 
A protease for digesting $30 \mathrm{~K}$ proteins, named $30 \mathrm{kP}$ protease A, was found in silkworm eggs, and selectively hydrolyzes the $30 \mathrm{kDa}$ yolk protein of silkworm. This exhibited a high expression level in late-pupal stages, by Northern blot [19]. We predict that during this period, some $30 \mathrm{~K}$ proteins in male pupa are enzymatically degraded, producing nutrition for the activities of the last stages, such as eclosion and mating.

\section{Low molecular weight proteins change in later pupal stages}

In addition to the low molecular weight lipoprotein $30 \mathrm{~K}$ protein, small proteins also showed remarkable variation in the silkworm hemolymph maps, especially at the $8^{\text {th }}$ day of pupation. Spots $\mathrm{H} 52$ and H53, considered pupa-specific proteins, were detected only in the $8^{\text {th }}$ day hemolymph of pupa, in the acidic area of the $2 \mathrm{D}$ map. These two proteins were identified as $32 \mathrm{kDa}$ apolipoproteins. In 2005, Kim investigated a similar protein, in the fall webworm, Hyphantrin. The cDNA for the Hyphantrin protein was expressed only during the middle and late pupal stages, by Northern blot [20], and was similar to the $32 \mathrm{kDa}$ apolipoprotein of silkworm in expression pattern and molecular weight. Spot H54 was more abundant at the $8^{\text {th }}$ day of pupation compared to the $3^{\text {rd }}$ day of the pupa and larval stages, and was barely detectable in the hemolymph at eclosion. This was identified as a diapause bioclock protein, EA4, which is an ATPase that measures time intervals as a diapause-duration clock. Its activity can be elevated transiently by dissociation of an inhibitory peptide under cold conditions [21]. Spots H55, H56 were identified as apolipophorin III proteins, which increased greatly in silkworm moth hemolymph. Adult moths depend on an abundance of lipids as high-powered energy sources for flight. Apolipophorin III is considered to have a key role in lipid transport systems, and serves as a reusable shuttle for transporting lipids to flight muscles, for use as fuel [22]. Although B. mori, as a domesticated insect, has almost lost flight capability over cultivation, many activities in the adult moth, such as mating or egg laying, still rely heavily on an efficient muscle system.

\section{Proteins involved in metamorphosis from larval to pupa}

During insect metamorphosis, the larval tissues are degraded, and this decomposition involves programmed cell death (PCD) triggered by ecdysteroids. Some proteins related to PCD were found by 2D-electrophoresis and MS. Beta-N-acetylglucosaminidase (spots H8, H9, $\mathrm{H} 10$ ) is a chitinolytic enzyme that hydrolyzes chitose to chitobiose, and has an important role in metamorphosis [23]. The molecule 20-hydroxyecdysone induces expression of beta-N-acetylglucosaminidase, and strong expression of beta- $\mathrm{N}$-acetylglucosaminidase in the latter stage of the fifth larval stage contributes to larval tissue degeneration and metamorphosis [24]. Juvenile hormone regulates growth and development in insects, and is protected from hydrolysis by general esterases by combining with juvenile hormone binding protein (JHBP) [25]. JHBP (spots H36, H37, H38) was detected in silkworm hemolymph from larval to moth stages, and showed higher expression in the larval stage. Imaginal disc growth factor (IDGF) (spots H17, H18, H19) is a polypeptide growth factor that stimulates the growth of imaginal disk cells. In the presence of 20-hydroxyecdysion, IDGF can be induced in the anterior silk gland, suggesting that IDGF is involved in PCD during silkworm metamorphosis [26].

\section{Proteins involved in food digestion and substance metabolism}

During the fifth instar of the larval stage, the silkworm digests an abundance of mulberry to accumulate energy for the non-feeding pupal and adult stages. Some of the enzymes involved in substance and energy metabolism were found in this stage. For instants, aldose reductase (spots H21, H22) is a member of the family of oxidoreductases that convert glucose to sorbitol in carbohydrate metabolism [27]. Glyoxylate reductase (spot H23) and hydroxypyruvate isomerase (spot H31) participate in glyoxylate and dicarboxylate metabolism. The former can catalyze glycolate to produce glyoxylate, while the latter interconverts aldoses and ketoses [28,29]. Aminoacylase (spots H15, H16) belongs to a family of hydrolases that catalyze the conversion of $\mathrm{N}$-acyl-L-amino acids to carboxylate and L-amino acids [30]. CI-8 (spot H12) of silkworms also showed high expression at the $6^{\text {th }}$ day of fifth instar. It is secreted by the fatbody during the feeding period, and sequestered in the fatbody after the onset of spinning [31]. It not only interacts with two polypetides, p29 and p60, in the midgut membrane, but also inhibits the $35-\mathrm{kDa}$ protease in the digesting juice of the larval midgut $[32,33]$. During the period of high consumption of mulberry, we hypothesize that up-regulation of $\mathrm{CI}-8$ is involved in regulating protease activity in mulberry digestion.

\section{Proteins related to immunity in silkworm hemolymph}

Silkworm hemolymph is involved in initiation of the immune response. An abundance of proteins related to immunity were also identified in this work, including hemolin (spots H48, H49), prophenoloxidase (spot H11), serine proteinases (spots H24, H26), paralytic peptidebinding protein (H39), and trypsin inhibitor (spots $\mathrm{H} 1$, $\mathrm{H} 13, \mathrm{H} 14)$. The prophenoloxidase activation system is an important defense system against parasite and pathogen invasion [34]. Some proteins of this complex system were also detected in silkworm hemolymph. Hemolin is 
a member of the pattern recognition proteins, which are induced after bacterial infection. Although it does not have direct antibacterial activity, it can trigger the prophenoloxidase cascade against bacterial infection, in combination with bacterial lipopolysaccharides [35]. Two serine proteases were also found in hemolymph, which shared $66 \%$ and $67 \%$ similarities to serine protease homologs (SPHs) purified from the plasma of Manduca sexta larvae. The SPHs of $M$. sexta are reported to bind to pattern recognition receptor and function as mediators to recruit prophenoloxidase and prophenoloxidase-activating protease to the site of infection [36]. Prophenoloxidase has long been considered a key enzyme in melanization, which is considered to be an effective defense against microorganisms. Without prophenoloxidase, the melanization of insects is almost completely inhibited [37].

\section{Other proteins}

Some novel silkworm hemolymph proteins were identified in this work. In this work, SP1 and SP2 were found in the hemolymph of silkworm larvae, and a new hemolymph storage protein (BGIBMGA009027) was identified, which shared high similarity and a similar expression pattern to SP2. Gelsolin (spot H20) is an actin-binding protein that interacts with actin in vitro to promote actin nucleation and actin filament formation. There are two forms of gelsolin in vertebrates, one secreted, and other cytoplasmic [38]. The secreted gelsolin of silkworm was first reported here, in the molecular range of $45 \mathrm{kDa}$, and by hemolymph map, was expressed from larvae to moth. It is presumed to be involved in the regulation of extracellular fluid viscosity, or in wound-healing [39]. Some protease inhibitors were present in silkworm hemolymph (spot H1, H12, H13). For example, inter-alpha-trypsin inhibitors (ITIH4) are a family of structurally related serine protease inhibitors in human plasma. Recent studies suggest they may function during infection by bacteria and viruses [40]. Finally, some proteins (H2, H3, H4, $\mathrm{H} 32, \mathrm{H} 51$ ) are not discussed here, even though they had strong expression and showed remarkable change during development and metamorphosis, because of inconclusive results from database searches. Future analysis of these proteins and their functions will contribute to our understanding of development and metamorphosis.

\section{Conclusions}

Proteomics research not only provides a method for investigating protein expression patterns, but also identifies lots of attractive candidates for further investigation. In this work, silkworm hemolymph from different stages was analyzed by proteomic tools. Some proteins, including $30 \mathrm{~K}$ proteins, low molecular weight lipoproteins, proteins related to $\mathrm{PCD}$, proteases, protease inhibitors, enzymes involved in metabolism, proteins related to immunity, and a few novel proteins were identified from silkworm hemolymph of different stages. In general, 2Delectrophoresis of silkworm proteins during development and metamorphosis provides information for studying the proteins in silkworm hemolymph. The newly established 2D map of silkworm hemolymph may be an important tool for understanding protein function in lepidopteran insects.

\section{Methods}

\section{Animals and sample preparation}

The B. mori strain p50 (DaZao), maintained at the Key Sericultural Laboratory of Agricultural Ministry, Southwest University, was used. Silkworms were reared on mulberry at $25^{\circ} \mathrm{C}$. On $1^{\text {st }}$ day of the fifth larval stage, male and female silkworms were determined using the following method. In females, a pair of round milky spots is located on right and left side of $8^{\text {th }}$ and $9^{\text {th }}$ abdominal segment. In males, a milky spot is located at the center of the ventral side between $8^{\text {th }}$ and $9^{\text {th }}$ abdominal segment [41]. Silkworms were pricked and squeezed gently to collect hemolymph from the $1^{\text {st }}$ day of fifth instar to eclosion. Each sample was collected from approximate 15 silkworms. Samples were centrifuged for $10 \mathrm{~min}$ at $12,000 \mathrm{rpm}$ at $4^{\circ} \mathrm{C}$, and stored in a lysis solution of $8 \mathrm{M}$ urea, $4 \%(\mathrm{w} / \mathrm{v})$ CHAPS, $1 \%(\mathrm{w} / \mathrm{v})$ dithiothreitol (DTT), and $1 \%(\mathrm{v} / \mathrm{v})$ protease inhibitors cocktail (Sigma P2714). Total protein content in the supernatant was determined by the method of Bradford [42].

\section{SDS-PAGE and 2D-PAGE}

SDS-PAGE was performed using a $4 \%$ stacking gel and $12 \%$ separating gel, and $15 \mu \mathrm{g}$ of each protein sample was loaded onto gels after dissolving in loading buffer and treating at $95^{\circ} \mathrm{C}$ for $5 \mathrm{~min}$. SDS-PAGE was carried out at $10 \mathrm{~mA}$ for stacking gel and $20 \mathrm{~mA}$ for separating gel until the bromophenol reached the end of the gel. Resolved proteins were stained with silver nitrate. Isoelectric focusing electrophoresis (IEF) was performed with the Multiphor II system (Amersham Biosciences). About $60 \mu \mathrm{g}$ protein was solubilized in rehydration solution (8.0 M urea, 2\% CHAPS, 0.8\% DTT, 0.5\% IPG buffer, pH 3-10, 0.002\% bromophenol blue) and applied to $13 \mathrm{~cm} \mathrm{pH} \mathrm{3-10} \mathrm{ReadyStrip} \mathrm{IPG} \mathrm{strips} \mathrm{(Amersham).}$ Rehydration was for $12 \mathrm{~h}$ at room temperature. IEF used a sequential gradient procedure of $100 \mathrm{~V}$ for $2 \mathrm{~h}$, $200 \mathrm{~V}$ for $1 \mathrm{~h}, 500 \mathrm{~V}$ for $1 \mathrm{~h}$, and $3500 \mathrm{~V}$ for $10 \mathrm{~h}$. The current limit is $50 \mu \mathrm{A}$ per IPGstrip. After IEF, strips were equilibrated in buffer A $(50 \mathrm{mM}$ Tris- $\mathrm{HCl}, \mathrm{pH} 8.8$, $6 \mathrm{M}$ urea, 30\% glycerol, 2\% SDS and $65 \mathrm{mM} \mathrm{DTT}$ ) for $15 \mathrm{~min}$, then re-equilibrated in buffer B containing 2.5\% iodoacetamide instead of DTT for $15 \mathrm{~min}$. Strips were loaded on $12.5 \%$ polyacrylamide gels for the second- 
dimension separation (SE 600 Vertical Gel Electrophoresis Unit). SDS-PAGE was carried out at $5 \mathrm{~mA}$ per gel for $20 \mathrm{~min}$, then $10 \mathrm{~mA}$ per gel until the bromophenol reached the end of the gel. Gels were stained with silver nitrate according to the Amersham 2D handbook and developed in rinse solution for approximate $5 \mathrm{~min}$ and transferred to stop solution before the background became dark [43]. At least three replicates were performed for each sample. Spots were scanned by highresolution imagescanner II (Amersham Bioscience) at 300 pixels, and analyzed by ImageMaster 2D 5.0 software (Amersham Bioscience).

\section{In-gel digestion and MALDI-TOF MS}

Protein spots were cut from the gel with a scalpel, and destained with $100 \mu \mathrm{L}$ of $30 \mathrm{mM}$ potassium, $100 \mathrm{mM}$ sodium thiosulfate $(1: 1, \mathrm{v} / \mathrm{v})$, and vortexed occasionally until the brown color disappeared completely. Pieces were rinsed three times with Milli-Q water. The supernatant was discarded and gel pieces were dehydrated with $100 \% \mathrm{ACN}$ for $5 \mathrm{~min}$, then rehydrated with $15 \mu \mathrm{L}$ of $50 \mathrm{mM}$ ammonium bicarbonate, containing $0.1 \mu \mathrm{g}$ of modified trypsin (Sigma). After digestion overnight at $37^{\circ}$ $\mathrm{C}$, peptides were extracted three times with $25 \mu \mathrm{L}$ of 50 $\mathrm{mM}$ ammonium bicarbonate containing 50\% ACN containing 5\% TFA. The supernatant was transferred into a new tube and the above step repeated. The combined extraction solution was concentrated to $5 \mu \mathrm{L}$ in a vacuum centrifuge (Thermo Savant, USA). The peptide mixture $(1 \mu \mathrm{L})$ was mixed with an equal volume of saturated CHCA solution containing $0.1 \%$ TFA and $50 \% \mathrm{ACN}$, and analyzed by a Voyager DE PRO MALDI-TOF MS (Applied Biosystems) using a delayed ion extraction, and positive ion reflection mode, at $20 \mathrm{kV}$ of accelerating voltage, $60-65 \%$ grid voltage, and 100 ns delay time. Spectra were acquired from m/z 800 to 2500 . Spectra were calibrated with trypsin auto-digestion ion peak $\mathrm{m} / \mathrm{z}$ (842.510 and 2211.1046) as internal standards. MS/MS analysis was performed on a 4700 MALDI-TOF/TOF mass spectrometer (Applied Biosystems). The peak were calibrated by default and smoothed. All peaks were deisotoped.

\section{Database searches}

Databases were constructed using "silkworm" as a key word in the NCBI protein database. Open reading frames were downloaded from silkDB http://silkworm.swu.edu. $\mathrm{cn} /$ silkdb/doc/download.html[44]. Combined databases containing 20,790 protein sequences were used to analyze peptide fingerprint masses using GPMAW software 6.0 [45]. The following parameters were used in all searches: maximum number of missed cleavages allowed was $=1$, mass tolerance was $=1 \mathrm{Da}$, and deisotoped masses of peaks were used for protein identification. Possible covalent modifications considered in search procedure were acetylation of the N-terminus. Identification criteria were based on the number and coverage of matched peptides: minimum peptides required to match $=5$, coverage of matched peptides $\geq 25 \%$ or the identification scores from software $\geq 85$. In addition, the consistency of theoretical molecular weight or pI of proteins with the observed molecular weight or pI from 2D map is an important reference for mass identification.

\section{Additional material}

Additional file 1: Identification of the main spots from development
and metamorphosis. a. Spot number, protein name, cell function,
access number in NCBI database, access number in silkworm DB
database by BGI Gene Finder, number of peptides matched/total
peptides, peptide coverage, score, theoretical molecular weight (Mr),
theoretical pl, matched peaks and corresponding sequence are indicated.
b. Some spots contained multiple proteins.
Additional file 2: List of $\mathbf{3 0} \mathbf{K}$ proteins from $2 \mathrm{D}$ maps and MALDI-
TOF MS. 15 spots from $2 \mathrm{D}$ gels of $3^{\text {rd }}$ day of pupation hemolymph were
excised and analyzed by MALDI-TOF MS. Five $30 \mathrm{~K}$ proteins were
detected in silkworm hemolymph, Bmlp1, Bmlp2, Bmlp3, Bmlp4 and
Bmlp7. Spot number, protein name, access number in NCBI database,
access number in silkworm DB database by BGI Gene Finder, number of
peptides matched/total peptides, peptide coverage, score, theoretical
molecular weight (Mr), theoretical pl, matched peaks and corresponding
sequence are indicated.

\section{Abbreviations}

VN: vitellogenin; SP1, SP2: storage protein 1, storage protein 2; Cl: chymotrypsin inhibitor; 2D-PAGE: two-dimensional ployacrylamide gel electrophoresis; MALDI-TOF MS: matrix-assisted laser desorption ionization time of flight mass spectrometry; SDS-PAGE: sodium dodecyl sulfate polyacrylamide gel electrophoresis; CHCA: $\alpha$-Cyano-4-hydroxycinnamic acid; TFA: trifluoroacetic acid; ACN: acetonitrile; PCD: programmed cell death; JHBP: juvenile hormone binding protein; IDGF: imaginal disc growth factor; SPHS: serine proteinase homologs; ITIH4: inter-alpha-trypsin inhibitor; RT-PCR: reverse transcription-PCR; PI: isoelectric point.

\section{Acknowledgements}

This work was supported by grants from the National Key Scientific and Technological Project (No. 2006AA10A117), Program for Changjiang Scholars and Innovative Research Team in University (No. IRT0750), and the National Natural Science Foundation (No. 30972147).

\section{Authors' contributions}

$\mathrm{YH}$ and PZ conceived the idea of proteomics study, participated in its design and performed major portion of the sample analysis. $Y Z$ and $X Z$ carried out sample preparation and 2DE analysis for silkworm hemolymph. FW and JG performed MS analysis and data analysis. QX conceived and supervised the study. All authors read and approved the final manuscript.

\section{Competing interests}

The authors declare that they have no competing interests.

Received: 12 April 2010 Accepted: 8 September 2010 Published: 8 September 2010

\section{References}

1. Zhejiang Agricultural University: Anatomy and physiology of silkworm. Beijing: Agriculture Press 1981, 73-78.

2. Telfer WH, Williams CM: Immunological studies on insect metamorphosis. Qualitative and quantitative description of the blood antigens of the cecropia silkworm. J Gen Physiol 1953, 36:389-413. 
3. Tojo S, Nagata M, Kobayashi M: Storage proteins in the silkworm, Bombyx mori. Insect Biochem 1980, 10:289-303.

4. Fujii T, Sakurai H, Izumi S, Tomino S: Structure of the gene for the arylphorin-type storage protein SP 2 of Bombyx mori. J Biol Chem 1989, 264:11020-11025.

5. Izumi S, Fujie A, Yamada S, Tomino S: Molecular properties and biosynthesis of major plasma proteins in Bombyx mori. Biochim Biophys Acta 1981, 670:222-229.

6. Xia Q, Zhou Z, Lu C, Cheng D, Dai F, Li B, Zhao P, Zha X, Cheng T, Chai C, Pan G, Xu J, Liu C, Lin Y, Qian J, Hou Y, Wu Z, Li G, Pan M, Li C, Shen Y, Lan X, Yuan L, Li T, Xu H, Yang G, Wan Y, Zhu Y, Yu M, Shen W, et al: A draft sequence for the genome of the domesticated silkworm (Bombyx mori). Science 2004, 306:1937-1940.

7. The genome of a lepidopteran model insect, the silkworm Bombyx mori. Insect Biochem Mol Biol 2008, 38:1036-1045.

8. Hou Y, Xia Q, Zhao P, Zou Y, Liu H, Guan J, Gong J, Xiang Z: Studies on middle and posterior silk glands of silkworm (Bombyx mori) using twodimensional electrophoresis and mass spectrometry. Insect Biochem Mol Biol 2007, 37:486-496

9. Hou Y, Zhao P, Liu HL, Zou Y, Guan J, Xia QY: Proteomics analysis of fat body from silkworm (Bombyx mori). Sheng Wu Gong Cheng Xue Bao 2007, 23:867-872.

10. Zhang P, Aso Y, Jikuya H, Kusakabe T, Lee JM, Kawaguchi Y, Yamamoto K, Banno Y, Fujii H: Proteomic profiling of the silkworm skeletal muscle proteins during larval-pupal metamorphosis. J Proteome Res 2007, 6:2295-2303

11. Li XH, Wu XF, Yue WF, Liu JM, Li GL, Miao YG: Proteomic analysis of the silkworm (Bombyx mori L.) hemolymph during developmental stage. $J$ Proteome Res 2006, 5:2809-2814.

12. Mine E, Izumi S, Katsuki M, Tomino S: Developmental and sex-dependent regulation of storage protein synthesis in the silkworm, Bombyx mori. Dev Biol 1983, 97:329-337.

13. Kajiwara H, Imamaki A, Nakamura M, Mita K, Xia Q, Ishizaka M: Proteome analysis of silkworm 2. Hemolymph. J Electrophoresis 2009, 53:27-31.

14. Furusawa T, Rakwal R, Nam HW, Hirano M, Shibato J, Kim YS, Ogawa Y, Yoshida Y, Kramer KJ, Kouzuma Y, Agrawal GK, Yonekura M: Systematic investigation of the hemolymph proteome of Manduca sexta at the fifth instar larvae stage using one- and two-dimensional proteomics platforms. J Proteome Res 2008, 7:938-959

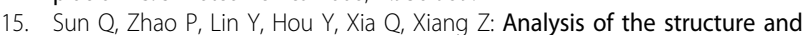
expression of the $30 \mathrm{~K}$ protein genes in silkworm, Bombyx mori. Insect Science 2007, 14:5-13.

16. Sakai N, Mori S, Izumi S, Haino-Fukushima K, Ogura T, Maekawa H, Tomino S: Structures and expression of mRNAs coding for major plasma proteins of Bombyx mori. Biochim Biophys Acta 1988, 949:224-232.

17. Zhu J, Indrasith LS, Yamashita O: Characterization of vitellin, egg-specific protein, and $30 \mathrm{kDa}$ protein from Bombyx eggs, and their fates during oogenesis and embryogenesis. Biochim Biophys Acta 1986, 882:427-436.

18. Chen Y, Yamashita O: Nonselective uptake of different $30 \mathrm{kDa}$ plasma proteins by developing ovaries of the silkworm. J Seri Sci Japan 1990, 59:202-209.

19. Maki N, Yamashita O: The $30 \mathrm{kP}$ protease A responsible for 30-kDa yolk protein degradation of the silkworm, Bombyx mori: CDNA structure, developmental change and regulation by feeding. Insect Biochem Mol Biol 2001, 31:407-413.

20. Kim HJ, Je HJ, Cheon HM, Kong SY, Han J, Yun CY, Han YS, Lee IH, Kang YJ, Seo SJ: Accumulation of $23 \mathrm{kDa}$ lipocalin during brain development and injury in Hyphantria cunea. Insect Biochem Mol Biol 2005, 35:1133-1141.

21. Isobe M, Kai H, Kurahashi T, Suwan S, Pitchayawasin-Thapphasaraphong S, Franz T, Tani N, Higashi K, Nishida H: The molecular mechanism of the termination of insect diapause, part 1: A timer protein, TIME-EA4, in the diapause eggs of the silkworm Bombyx mori is a metallo-glycoprotein. Chembiochem 2006, 7:1590-1598.

22. Weers PM, Ryan RO: Apolipophorin III: a lipid-triggered molecular switch. Insect Biochem Mol Biol 2003, 33:1249-1260.

23. Nagamatsu Y, Yanagisawa I, Kimoto M, Okamoto E, Koga D: Purification of a chitooligosaccharidolytic beta-N-acetylglucosaminidase from Bombyx mori larvae during metamorphosis and the nucleotide sequence of its cDNA. Biosci Biotechnol Biochem 1995, 59:219-225.
24. Zen KC, Choi HK, Krishnamachary N, Muthukrishnan S, Kramer KJ: Cloning, expression, and hormonal regulation of an insect beta- $\mathrm{N}$ acetylglucosaminidase gene. Insect Biochem Mol Biol 1996, 26:435-444.

25. Touhara $K$, Bonning BC, Hammock BD, Prestwich GD: Action of juvenile hormone $(\mathrm{JH})$ esterase on the $\mathrm{JH}-\mathrm{JH}$ binding protein complex. An in vitro model of $\mathrm{JH}$ metabolism in a caterpillar. Insect Biochem Mol Biol 1995, 25:727-734.

26. Tsuzuki S, Iwami M, Sakurai S: Ecdysteroid-inducible genes in the programmed cell death during insect metamorphosis. Insect Biochem Mol Biol 2001, 31:321-331

27. Bagnasco SM, Uchida S, Balaban RS, Kador PF, Burg MB: Induction of aldose reductase and sorbitol in renal inner medullary cells by elevated extracellular NaCl. Proc Natl Acad Sci USA 1987, 84:1718-1720.

28. Tolbert NE, Yamazaki RK, Oeser A: Localization and properties of hydroxypyruvate and glyoxylate reductases in spinach leaf particles. $J$ Biol Chem 1970, 245:5129-5136.

29. De Windt FE, Van der Drift C: Purification and some properties of hydroxypyruvate isomerase of Bacillus fastidiosus. Biochim Biophys Acta 1980, 613:556-562.

30. Fones WS, Lee $\mathrm{M}$ : Hydrolysis of $\mathrm{N}$-acyl derivatives of alanine and phenylalanine by acylase I and carboxypeptidase. J Biol Chem 1953, 201:847-856.

31. Shirai K, Fujii H, Doira H, Iwamoto H: Synthesis and resorption of a humoral chymotrypsin inhibitor, $\mathrm{Cl}-8$, by fat body of the silkworm, Bombyx mori. Insect Biochem Mol Biol 2000, 30:363-368.

32. Ueno Y, He N, Ujita M, Yamamoto K, Banno Y, Fujii H, Aso Y: Silkworm midgut proteins interacting with a hemolymph protease inhibitor, $\mathrm{Cl}-8$. Biosci Biotechnol Biochem 2006, 70:1557-1563.

33. Jiang $Y$, Shirai K, Okido T, Banno Y, Fujji H: Purification of $35 \mathrm{~K}$ protease from the digestive juice of Bombyx mori. J Insect Biotechnol Sericol 2000, 69:47-53.

34. Ashida M: The prophenoloxidase cascade in insect immunity. Res Immunol 1990, 141:908-910.

35. Terenius O, Bettencourt R, Lee SY, Li W, Soderhall K, Faye I: RNA interference of Hemolin causes depletion of phenoloxidase activity in Hyalophora cecropia. Dev Comp Immunol 2007, 31:571-575.

36. Yu XQ, Jiang $H$, Wang $Y$, Kanost MR: Nonproteolytic serine proteinase homologs are involved in prophenoloxidase activation in the tobacco hornworm, Manduca sexta. Insect Biochem Mol Biol 2003, 33:197-208.

37. Shiao SH, Higgs S, Adelman Z, Christensen BM, Liu SH, Chen CC: Effect of prophenoloxidase expression knockout on the melanization of microfilariae in the mosquito Armigeres subalbatus. Insect Mol Biol 2001 10:315-321.

38. Nodes BR, Shackelford JE, Lebherz HG: Synthesis and secretion of serum gelsolin by smooth muscle tissue. J Biol Chem 1987, 262:5422-5427.

39. Stella MC, Schauerte H, Straub KL, Leptin M: Identification of secreted and cytosolic gelsolin in Drosophila. J Cell Biol 1994, 125:607-616.

40. Pineiro M, Andres M, Iturralde M, Carmona S, Hirvonen J, Pyorala S, Heegaard PM, Tjornehoj K, Lampreave F, Pineiro A, Alava MA: ITIH4 (interalpha-trypsin inhibitor heavy chain 4) is a new acute-phase protein isolated from cattle during experimental infection. Infect Immun 2004, 72:3777-3782.

41. Singh T, SaratChandra B: Silkworm and its Races. Principles and Techniques of Silkworm Seed Production New Delhi: Discovery Publishing House, 12004 2:57.

42. Bradford MM: A rapid and sensitive method for the quantitation of microgram quantities of protein utilizing the principle of protein-dye binding. Anal Biochem 1976, 72:248-254

43. Berkelman T, Stenstedt T: 2-D electrophoresis. Using immobilized pH gradients. Principle and methods Sweden; Amersham Pharmacia Biotech $1998,87$.

44. Duan J, Li R, Cheng D, Fan W, Zha X, Cheng T, Wu Y, Wang J, Mita K, Xiang Z, Xia Q: SilkDB v2.0: a platform for silkworm (Bombyx mori) genome biology. Nucleic Acids Res 2008, 38:D453-456.

45. Peri S, Steen H, Pandey A: GPMAW-a software tool for analyzing proteins and peptides. Trends Biochem Sci 2001, 26:687-689.

doi:10.1186/1477-5956-8-45

Cite this article as: Hou et al:: Comparative analysis of proteome maps of silkworm hemolymph during different developmental stages.

Proteome Science 2010 8:45. 